\title{
SCIDOC
}

\author{
International Journal of Dentistry and Oral Science (IJDOS) \\ ISSN: 2377-8075
}

\section{Assessment Of Satisfactory Levels among Female Complete Denture Patients}

\section{Research Article}

Fathima Bareera Rezvi ${ }^{1}$, Revathi Duraisamy ${ }^{2 *}$, Manjari Chaudhary ${ }^{3}$

${ }^{1}$ Saveetha Dental College and Hospitals, Saveetha Institute of Medical and Technical Sciences, Saveetha University, Chennai, India.

${ }^{2}$ Saveetha Dental College and Hospitals, Saveetha Institute of Medical and Technical Sciences, Saveetha University, Chennai, 600077, India.

${ }^{3}$ Saveetha Dental College and Hospitals, Saveetha Institute of Medical and Technical Sciences, Saveetha University, Chennai, 600077, India.

\section{Abstract}

Complete dentures are important in order to improve mastication, aesthetic appearance and phonetics in completely edentulous patients. The feedback and follow up of patients is important. This helps us to correct minor problems and complications faced by the denture wearers. Ill fitting or uncomfortable dentures may have adverse effects on the soft tissues and hence the oral health of the patient. Patient satisfaction is required to assess the quality of treatment. The aim of the study was to assess the satisfaction levels among female complete denture patients who visited Saveetha Dental College. A survey was conducted among 50 patients who had received complete dentures from Saveetha Dental College, from the time period of June 2019 to March 2020. A number of questions on the levels of satisfaction was asked. Patient records were reviewed and 50 complete denture female patients between the age of 45-55 were selected. Descriptive statistics, cross tabulation and chi-square test were done by SPSS IBM software 20.0. There was no association between age and overall satisfaction ( $p>0.05)$. Most patients were satisfied with their appearance and overall. Within the limits of the study satisfaction among female complete denture patients was assessed. While most of them were satisfied with their appearance and overall satisfaction, dissatisfaction was present among most patients in the categories of chewing, retention, stability and ability to speak.

Keywords: Complete Denture; Satisfaction; Chewing; Retention; Stability.

\section{Introduction}

Edentulism is an irreversible condition in oral health. Complete denture is defined as a dental prosthesis which replaces the entire dentition and its associated structures of maxilla and mandible [1]. It is stated by Zou et al, that complete dentures are preferred by most edentulous patients, as they provide a pleasing appearance, good aesthetics and help to maintain normal speech, as well as provide occlusal support and mastication of food [2]. Complete dentures are important to improve mastication, aesthetics and phonetics of completely edentulous patients. Complete dentures should be comfortable and should positively contribute to the health of the denture supporting tissues [3].

Complaints in complete denture are most commonly due to pain, pressure, looseness, poor function and appearance [4]. The follow up of these patients is very important as ill fitting or uncomfortable dentures have adverse effects on denture supporting tissues, hence affecting oral health [5]. Loss of natural teeth has significant effect on appearance, aesthetics and functions of the individual.Some patients find it difficult to cope with well designed dentures because of anatomical features, resorbed residual ridges, proximity of the neurovascular bundle or physical factors leading to lack of muscular control, while some patients with similar conditions seem to manage well [6]. Some studies also state that completely edentulous patients may fall into depression [7]. Patient satisfaction is critical to determine the success, failure or the quality of complete denture treatment [8]. Patient perceptions are fundamental for the improvement of health and quality, so methods for assessing patient feedback on satisfaction, care, experience and treatment outcomes are important $[9,10]$.

Majority of the patients express satisfaction with complete den-

*Corresponding Author:

Revathi Duraisamy,

Saveetha Dental College and Hospitals, Saveetha Institute of Medical and Technical Sciences, Saveetha University, Chennai, 600077, India.

Tel: 7598267022

E-mail: revathid.sdc@saveetha.com

Received: November 10, 2020

Accepted: December 15, 2020

Published: December 18, 2020

Citation: Fathima Bareera Rezvi, Revathi Duraisamy, Manjari Chaudhary. Assessment Of Satisfactory Levels among Female Complete Denture Patients. Int J Dentistry Oral Sci. 2020;7(12):1265-1270. doi: http://dx.doi.org/10.19070/2377-8075-20000250

Copyright: Revathi Duraisamy ${ }^{\circ} 2020$. This is an open-access article distributed under the terms of the Creative Commons Attribution License, which permits unrestricted use, distribution and reproduction in any medium, provided the original author and source are credited. 
tures that are designed and constructed well, but yet some groups remain dissatisfied [11]. Patient satisfaction with their complete dentures may be considered as the ultimate goal of treatment as it has a strong association with oral health related quality of life [12]. Due to ill fitting dentures and discomfort caused due to it, patients are hesitant to wear the dentures and doubt the treatment and the ability of the dentist to provide quality treatment [13]. According to some studies, four recall appointments after 10 days, 3 weeks, 6 weeks and 3 months should be arranged from the day of denture delivery $[11,14]$. Patients evaluation of the prosthesis may correlate with clinician's assessment or with the anatomic variations [15]. Sometimes, there is said to be a discrepancy between the perceptions of a dentist and the expectations of a patient [16]. Additionally, a small number of denture wearers cannot adapt to the fabricated dentures and hence are dissatisfied 9.

Previously our team had conducted numerous clinical trials [1723] systematic reviews [24-29] and survey [30] over the past five years. Over time, advancements have been made in the fabrication of complete denture along with improvement in adhesives have been made for patients with high expectations. Still, dissatisfaction among denture wearers is common [31]. Thus the aim of this study was to assess the satisfaction levels among complete denture patients who visited Saveetha Dental College.

\section{Materials and Methods}

Our study population consisted of 50 female patients, who got their complete denture fabricated from Saveetha Dental College. A questionnaire with the criteria for satisfactory levels was developed. Ethical clearance was obtained from the institutional ethics board SDC/SIHEC/2020/DIASDATA/0619-0320.

The data was retrieved from 86,000 patients' records among which 50 female patients were selected based on the inclusion criteria. Phone calls were made to the patient and the patient was asked about their satisfaction levels. This study involved 3 reviewers. Data included the study were from the time period of June 2019 to March 2020. Certain measurements were taken in order to minimize bias, such as simple random sampling, collecting more data sources and including the data from the institute.

\section{Inclusion criteria:}

- Patients who received complete denture prosthesis from saveetha dental college

- Female patients

\section{Exclusion criteria:}

- Patient with removable partial denture

- Patient with implant supported denture

- Male patients

The data was then entered in Microsoft Excel and was analysed using SPSS IBM software version 20.0. Descriptive statistics were calculated to explore the demographic data. A cross tabulation analysis was conducted to examine the categorical variables. Chisquare test was used to identify the presence of significance between the variables.

\section{Questionnaire}

1. How satisfied are you with the ability to chew hard foods? 2. How satisfied are you with the ability to chew soft foods?

3. How satisfied are you with the retention of your denture?

4. How satisfied are you with the stability of your denture while eating or talking?

5. How satisfied are you in your ability to insert/remove the denture?

6. How satisfied are you in your ability to speak with the denture?

7. How satisfied are you with the aesthetic appearance?

8. Overall satisfaction with your denture?

\section{Results and Discussion}

The following results were obtained from our study. For the question, Ability to chew hard food, $32 \%$ of the complete denture patients answered For nothing, while 24\% answered Very, followed by $18 \%$ of them answered Enough, 14\% answered Little and $12 \%$ answered Totally (Figure 1). For the question, Ability to chew soft food, $26 \%$ of the complete denture patients answered Little, while $24 \%$ answered Totally, followed by $22 \%$ of them answered For nothing, 18\% answered Enough and 10\% answered Very (Figure 2). For the question, Satisfaction with retention, $28 \%$ of the complete denture patients answered For nothing, while $20 \%$ answered Very and Little, followed by $16 \%$ of them answered Enough and Totally (Figure 3). For the question, Satisfaction with stability, $24 \%$ of the complete denture patients answered For nothing and Enough, followed by $22 \%$ of them

Figure 1. This bar chart shows the answer for the question - How satisfied are you with the ability to chew hard foods? $\mathrm{X}$ axis shows the answers with the options of For nothing or Little or Enough or Very or Totally and Y axis shows the frequency of each answer. Most common answer - For nothing (32\%), while Very (24\%) being the second most common answer, followed by Enough (18\%), Little (14\%) and Totally (12\%).

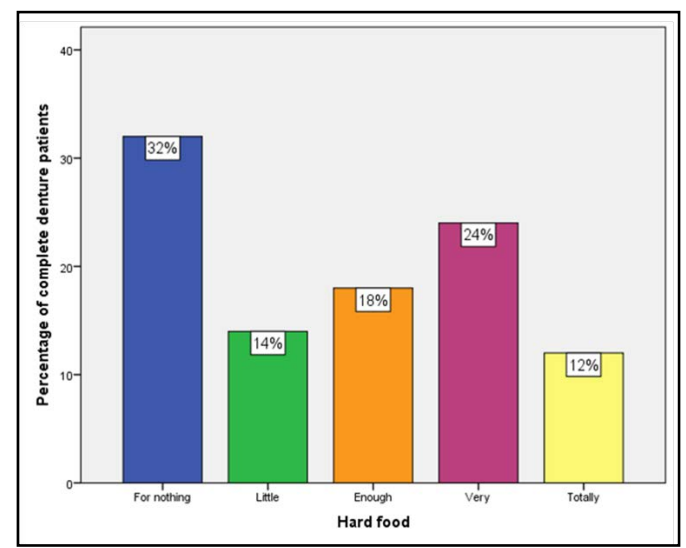


answered Totally, while 18\% answered Little and 12\% answered Very (Figure 4). For the question, Ability to insert/remove the denture, $28 \%$ of the complete denture patients answered Very, while $26 \%$ answered For nothing, followed by $20 \%$ of them answered Totally, 14\% answered Little and 12\% answered Enough (Figure 5). For the question, Ability to speak, 26\% of the complete denture patients answered For nothing, while $22 \%$ answered Very and Totally, followed by $18 \%$ of them answered Enough and $12 \%$ answered Little (Figure 6). For the question concerning the aesthetic appearance, $26 \%$ of complete denture patients answered Totally, while $22 \%$ answered Enough, followed by $20 \%$ of them answered Little, 18\% answered For nothing and 14\% answered Very (Figure 7). For the question concerning the overall satisfaction, $28 \%$ of them answered Totally, while $20 \%$ answered Little, followed by $18 \%$ of them answered For nothing and Very and lastly 16\% answered Enough (Figure 8). The association between age and overall satisfaction was analysed and our study showed that there was no significant association between age and overall satisfaction ( $p>0.05)$ (Figure 9).

According to William James, psychologist, emotion is the state of mind that manifests itself by perceptible change in the body, which is important in the development of personality. Attitude of the patient, determines the success or failure, despite the technicality of the complete denture. Based on the ability to chew soft and hard food, Bilhan et al also states that difficulty was experienced by his group of subjects [32]. This could be due to maladaptiveness, psychological factors, insufficient patient-dentist communication. Satisfaction based on retention and stability was assessed and this is also in line with Bilhan et al. Most of his patients in his study were dissatisfied with the retention and stability of the delivered denture. This could be due to loose dentures, ill

Figure 2. This bar chart shows the answer for the question - How satisfied are you with the ability to chew soft foods? $\mathrm{X}$ axis shows the answers with the options of For nothing or Little or Enough or Very or Totally and Y axis shows the frequency of each answer. Most common answer - Little (26\%), while Totally $(24 \%)$ being the second most common answer, followed by For nothing $(22 \%)$, Enough $(18 \%)$ and Very $(10 \%)$.

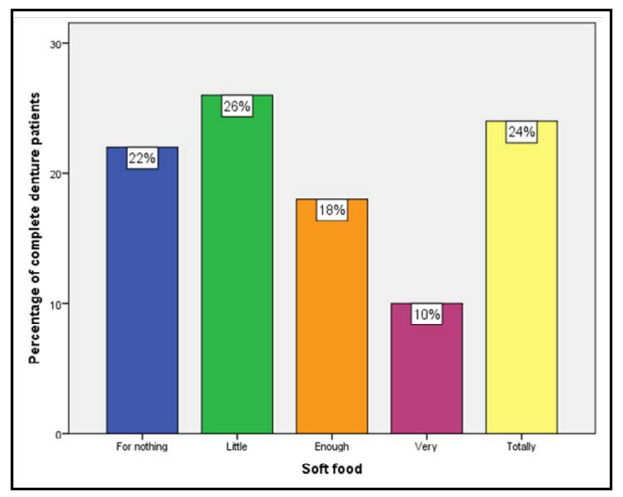

Figure 3. This bar chart shows the answer for the question - How satisfied are you with the retention of your denture? $\mathrm{X}$ axis shows the answers with the options of For nothing or Little or Enough or Very or Totally and Y axis shows the frequency of each answer. Most common answer - For nothing (28\%), while Very $(20 \%)$ and Little $(20 \%)$ being the second most common answer, followed by Enough (16\%), and Totally (16\%).

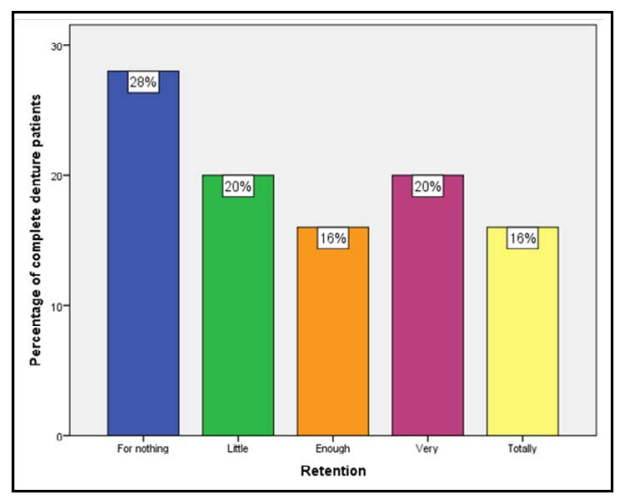

Figure 4. This bar chart shows the answer for the question - How satisfied are you with the stability of your denture while eating or talking? $\mathrm{X}$ axis shows the answers with the options of For nothing or Little or Enough or Very or Totally and Y axis shows the frequency of each answer. Most common answer For nothing (24\%) and Enough (24\%), while Totally $(22 \%)$ being the second most common answer, followed Little (18\%) and Very (12\%).

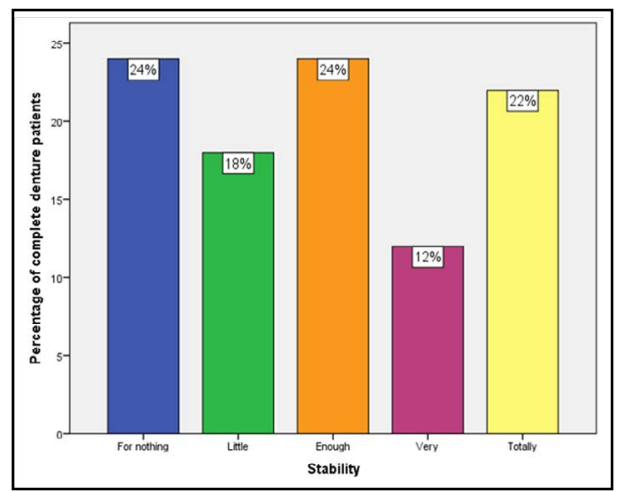


Figure 5. This bar chart shows the answer for the question - How satisfied are you with the ability to insert/remove your denture? $\mathrm{X}$ axis shows the answers with the options of For nothing or Little or Enough or Very or Totally and Y axis shows the frequency of each answer. Most common answer - Very $(28 \%)$, while For nothing (26\%) being the second most common answer, followed by Totally (20\%), Little (14\%) and Enough (12\%).

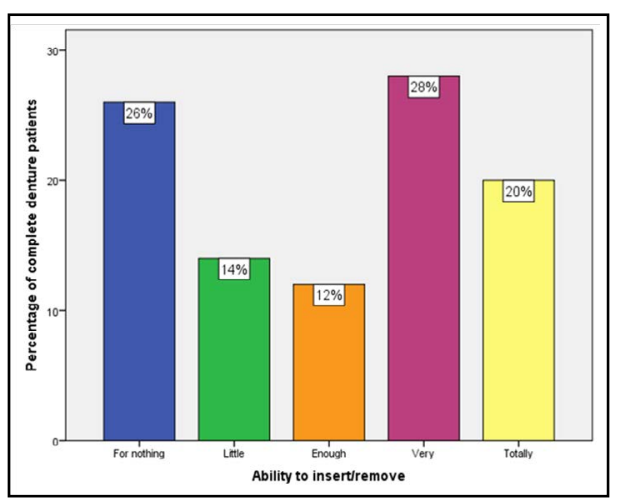

Figure 6. This bar chart shows the answer for the question - How satisfied are you with the ability to speak? $\mathrm{X}$ axis shows the answers with the options of For nothing or Little or Enough or Very or Totally and Y axis shows the frequency of each answer. Most common answer - For nothing (26\%), while Very $(22 \%)$ and Totally $(22 \%)$ being the second most common answer, followed by Enough (18\%) and Little (12\%).

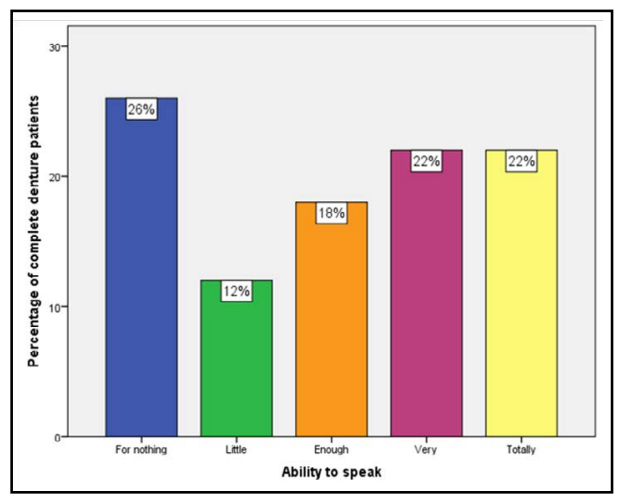

Figure 7. This bar chart shows the answer for the question - How satisfied are you with the aesthetic appearance? $\mathrm{X}$ axis shows the answers with the options of For nothing or Little or Enough or Very or Totally and Y axis shows the frequency of each answer. Most common answer - Totally (26\%), while Enough (22\%) and being the second most common answer, followed by Little (20\%), For nothing (18\%) and Very (14\%).

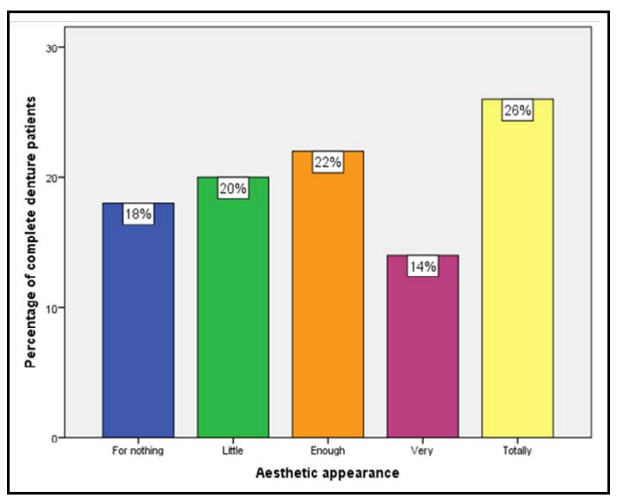

Figure 8. This bar chart shows the answer for the question - what is your overall satisfaction? $\mathrm{X}$ axis shows the answers with the options of For nothing or Little or Enough or Very or Totally and Y axis shows the frequency of each answer. Most common answer - Totally (28\%), while Little (20\%) being the second most common answer, followed by For nothing $(18 \%)$, Very $(18 \%)$ and Enough $(16 \%)$.




Figure 9. This bar chart shows the association between age and overall satisfaction levels of the patients. $\mathrm{X}$-axis represents the age group $45-55$ years and Y-axis represents the number of complete denture patients with different answers for overall satisfaction. There is no association between age and overall satisfaction levels, hence statistically not significant. [Pearson's Chi Square value: $43.203 \mathrm{a}, \mathrm{df}=40, \mathrm{p}$ value $=0.336(>0.05)$ ]

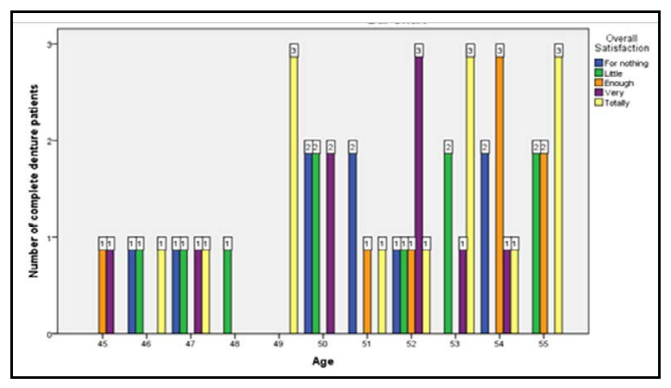

fitting dentures or residual bone resorption with time in females. Sowers et al states that due to hormonal changes during menopause, there is an increase in bone resorption [33]. This is seen in women in the age group of 45 and above as menopause begins at this stage.

Based on satisfaction with insertion and removal of denture, most patients were dissatisfied according to the questionnaire. This is in line with the study done by P. Deekshita et al [34]. When focusing on the satisfaction of the ability to speak, most women were dissatisfied in this category. This in line with Singh et al [35]. Poor retention and stability lead to looseness of the denture and hence difficulty in speech. Most patients were satisfied in the aesthetic aspect. Musavi et al also states the same in his study. This could be due to the fact that aesthetic needs are met during denture insertion and denture delivery [36]. Overall satisfaction was positive in this study as most patients were satisfied with the denture overall. This was also seen in similar studies by Sharafat et al [37] and few other studies 4 [38]. These patients are less meticulous with realistic expectations. But this contradicts with Singh et al [35]. This could be due to patients with low self esteem or lack of confidence leading to overall dissatisfaction. In such cases more effective communication to be established between dentist and patient along with counselling and psychological support.

Limitations of the study include smaller sample size, education level of the patient. Hence for future scope a larger sample size could be used with better knowledge and treatment modalities and better efficient communication with psychological support given to the patients.

\section{Conclusion}

Within the limits of the study, satisfaction among complete denture patients on function, comfort and appearance was assessed. Although dissatisfaction was present among most patients in the categories of chewing, retention, stability and the ability to speak, the majority of patients were satisfied with their appearance and overall satisfaction with the denture. But there was no association between age and overall satisfaction levels among female complete denture patients, $\mathrm{p}$ value $=0.336(>0.05)$. Factors such as educational status, socio-economic status, psychological levels of the patients could be additionally evaluated in order to get a better statistical outcome.

\section{Acknowledgement}

Thanks to Saveetha Dental college for allowing me to review the case sheets.

\section{Authors Contribution}

First author (Fathima Bareera Rezvi) performed the analysis, and interpretation and wrote the manuscript. Second author (Dr. Revathi Duraisamy) contributed to conception, data design, analysis, interpretation and critically revised the manuscript. Third author(Dr.Manjari Chaudhary) participated in the study and revised the manuscript. All the three authors have discussed the results and contributed to the final manuscript.

\section{References}

[1]. Hemmings KW, Schmitt A, Zarb GA. Complications and maintenance requirements for fixed prostheses and overdentures in the edentulous mandible: a 5-year report. Int J Oral Maxillofac Implants. 1994 Mar-Apr;9(2):191-6. PMID: 8206555 .

[2]. Zou Y, Zhan D. Patients' expectation and satisfaction with complete denture before and after the therapy. Vojnosanit Pregl. 2015 Jun;72(6):495-8. PMID: 26226720.

[3]. The british society for the study of prosthetic dentistry-founded in 1953 . J Prosthet Dent. 2000 Aug;84(2):123-4. PMID: 10946325.

[4]. Yoshizumi DT. An evaluation of factors pertinent to the success of complete denture service. The Journal of Prosthetic Dentistry. 1964 Sep 1;14(5):86678.

[5]. Kivovics P, Jáhn M, Borbély J, Márton K. Frequency and location of traumatic ulcerations following placement of complete dentures. Int J Prosthodont. 2007 Jul-Aug;20(4):397-401. PMID: 17695871.

[6]. Berg E, Johnsen TB, Ingebretsen R. Psychological variables and patient acceptance of complete dentures. Acta Odontol Scand. 1986 Feb;44(1):17-22. PMID: 3456689.

[7]. Jyothi S, Robin PK, Ganapathy D. Periodontal health status of three different groups wearing temporary partial denture. Research Journal of Pharmacy and Technology. 2017 Dec 1;10(12):4339-42.

[8]. Ashok NG, Ganapathy D. Evaluation of post-operative complaints in complete denture and removable partial denture wearers: A questionnaire based study. Journal of Pharmaceutical Sciences and Research. 2017 Sep $1 ; 9(9): 1438$

[9]. Carlsson GE, Omar R. The future of complete dentures in oral rehabilitation. A critical review. J Oral Rehabil. 2010 Feb;37(2):143-56. PMID: 20002536.

[10]. Marchini JF, Souza FL, Schmidt A, Cunha SF, Salgado W Jr, Marchini JS, et al. Low educational status, smoking, and multidisciplinary team experience predict hospital length of stay after bariatric surgery. Nutr Metab Insights. 2012 Oct 15;5:71-6. PMID: 23882150.

[11]. Langer A, Michman J, Seifert I. Factors influencing satisfaction with complete dentures in geriatric patients. The Journal of Prosthetic Dentistry. 1961 Nov 1;11(6):1019-31.

[12]. Foeller ML. Satisfaction and quality: patient perspectives in medical care. 2000.

[13]. Brunello DL, Mandikos MN. Construction faults, age, gender, and relative medical health: factors associated with complaints in complete denture patients. J Prosthet Dent. 1998 May;79(5):545-54. PMID: 9597608.

[14]. Bergman B, Hugoson A, Olsson CO. Caries, periodontal and prosthetic findings in patients with removable partial dentures: a ten-year longitudinal 
study. J Prosthet Dent. 1982 Nov;48(5):506-14. PMID: 6754910.

[15]. Awad MA, Feine JS. Measuring patient satisfaction with mandibular prostheses. Community Dent Oral Epidemiol. 1998 Dec;26(6):400-5. PMID: 9870539 .

[16]. Weinstein M, Schuchman J, Lieberman J, Rosen P. Age and denture experience as determinants in patient denture satisfaction. J Prosthet Dent. 1988 Mar;59(3):327-9. PMID: 3162273.

[17]. Duraisamy R, Krishnan CS, Ramasubramanian H, Sampathkumar J, Mariappan S, Navarasampatti Sivaprakasam A. Compatibility of Nonoriginal Abutments With Implants: Evaluation of Microgap at the Implant-Abutment Interface, With Original and Nonoriginal Abutments. Implant Dent. 2019 Jun;28(3):289-295. PMID: 31124826.

[18]. Ganapathy D, Sathyamoorthy A, Ranganathan H, Murthykumar K. Effect of Resin Bonded Luting Agents Influencing Marginal Discrepancy in All Ceramic Complete Veneer Crowns. J Clin Diagn Res. 2016 Dec;10(12):ZC67ZC70. PMID: 28209008.

[19]. Vijayalakshmi B, Ganapathy D. Medical management of cellulitis. Research Journal of Pharmacy and Technology. 2016 Nov 28;9(11):2067-70.

[20]. Ashok V, Nallaswamy D, Benazir Begum S, Nesappan T. Lip Bumper Prosthesis for an Acromegaly Patient: A Clinical Report. J Indian Prosthodont Soc. 2014 Dec;14(Suppl 1):279-82. PMID: 26199531.

[21]. Venugopalan S, Ariga P, Aggarwal P, Viswanath A. Case Report: Magnetically retained silicone facial prosthesis. Nigerian journal of clinical practice. 2014 Mar 27;17(2):260-4.

[22]. Basha FY, Ganapathy D, Venugopalan S. Oral hygiene status among pregnant women. Research Journal of Pharmacy and Technology. 2018 Jul 31;11(7):3099-102.

[23]. Ajay R, Suma K, Ali SA, Kumar Sivakumar JS, Rakshagan V, Devaki V, et al. Effect of Surface Modifications on the Retention of Cement-retained Implant Crowns under Fatigue Loads: An In vitro Study. J Pharm Bioallied Sci. 2017 Nov; 9(Suppl 1): S154-S160. PMID: 29284956.

[24]. Kannan A, Venugopalan S. A systematic review on the effect of use of impregnated retraction cords on gingiva. Research Journal of Pharmacy and Technology. 2018 May 30;11(5):2121-6.

[25]. Ganapathy DM, Kannan A, Venugopalan S. Effect of coated surfaces influencing screw loosening in implants: A systematic review and meta-analysis. World Journal of Dentistry. 2017 Nov;8(6):496-502.

[26]. Ranganathan H, Ganapathy DM, Jain AR. Cervical and Incisal Marginal
Discrepancy in Ceramic Laminate Veneering Materials: A SEM Analysis. Contemp Clin Dent. 2017 Apr-Jun;8(2):272-278. PMID: 28839415.

[27]. Subasree S, Murthykumar K. Effect of aloe vera in oral health-A review. Research Journal of Pharmacy and Technology. 2016 May 1;9(5):609.

[28]. Selvan SR, Ganapathy D. Efficacy of fifth generation cephalosporins against methicillin-resistant Staphylococcus aureus-A review. Research Journal of Pharmacy and Technology. 2016 Oct 28;9(10):1815-8.

[29]. Jain AR, Nallaswamy D, Ariga P, Ganapathy DM. Determination of correlation of width of maxillary anterior teeth using extraoral and intraoral factors in Indian population: A systematic review. World J Dent. 2018 Jan;9:68-75.

[30]. Ashok V, Suvitha S. Awareness of all ceramic restoration in rural population. Research Journal of Pharmacy and Technology. 2016 Oct 28;9(10):1691-3.

[31]. Panchevska S, Elenchevski S, Janeva N, Mijoska A. Satisfaction of complete denture wearers. Medicinski pregled. 2018;71(7-8):247-9.

[32]. Bilhan H, Erdogan O, Ergin S, Celik M, Ates G, Geckili O. Complication rates and patient satisfaction with removable dentures. J Adv Prosthodont. 2012 May;4(2):109-15. PMID: 22737317.

[33]. Sowers MR, Zheng H, Greendale GA, Neer RM, Cauley JA, Ellis J, et al. Changes in bone resorption across the menopause transition: effects of reproductive hormones, body size, and ethnicity. J Clin Endocrinol Metab. 2013 Jul; 98(7): 2854-63. PMID: 23666961.

[34]. Deeksheetha P, Duraisamy R, Ganapathy D. Post insertion complications in patients' wearing conventional complete denture and bio functional prosthetic system dentures. Drug Invention Today. 2019 Sep 1;11(9).

[35]. Singh H, Sharma S, Singh S, Wazir N, Raina R. Problems faced by complete denture-wearing elderly people living in jammu district. J Clin Diagn Res. 2014 Dec;8(12):ZC25-7. PMID: 25654025.

[36]. Musavi SA, Eslami H, Fakhrzadeh V, Dabaghi-Tabriz F, Rahbar M, Khadem-Neghad S, et al. Evaluation of Patients' Satisfaction with the Complete Denture made in Prosthodontics Department of Dentistry Faculty, Tabriz, Iran 2017. Advances in Bioscience and Clinical Medicine. $2018 \mathrm{Apr}$ 30;6(2):9-13

[37]. Sharafat F. Assessment of the relation between patients attitude and patients satisfaction with complete dentures. Pak Oral Dent J. 2008;28:305-8.

[38]. Sheppard IM, Schwartz LR, Sheppard SM. Oral status of edentulous and complete denture-wearing patients. J Am Dent Assoc. 1971 Sep;83(3):61420. PMID: 4935065. 